Brazilian Journal

of Chemical

\title{
BIOLOGICAL PHOSPHATE REMOVAL USING A DEGRADABLE CARBON SOURCE PRODUCED BY HYDROTHERMAL TREATMENT OF EXCESS SLUDGE
}

\author{
L. H. Haraguchi ${ }^{1}$, M. Fujita ${ }^{2}$, H. Daimon ${ }^{3 *}$, K. Fujie ${ }^{3}$ and R. S. Mohamed ${ }^{1}$ \\ ${ }^{1}$ School of Chemical Engineering, State University of Campinas, \\ Cx. P. 6066, CEP 13081-970, Campinas - São Paulo, Brazil \\ ${ }^{2}$ Interdisciplinary Graduate School of Medicine and Engineering, \\ University of Yamanashi, 4-3-11 Takeda, Kofu, Yamanashi 400-8511, Japan. \\ ${ }^{3}$ Department of Ecological Engineering, Toyohashi University of Technology \\ Hibarigaoka 1-1, Phone/Fax: +(81) (532) 44-6910, \\ Tempaku-cho, Toyohashi, Aichi 441-8580, Japan. \\ E-mail: daimon@eco.tut.ac.jp
}

(Received: May 19, 2004 ; Accepted: October 18, 2005)

\begin{abstract}
The possibility of reusing excess sludge treated by hydrothermal reaction for the purpose of improving the efficiency of the enhanced biological phosphate removal (EBPR) process was investigated. Excess sludge from a fish-processing industry located in Japan was treated in high-temperature and high-pressure water, at a reaction temperature ranging from 200 to $400^{\circ} \mathrm{C}$, a pressure of 1.8 to $30 \mathrm{MPa}$ and a constant reaction time of $7 \mathrm{~min}$. For the conditions tested, the results showed that when the reaction temperature was increased the content of readily biodegradable substrate in the total $\mathrm{COD}_{\mathrm{Cr}}$ increased. In addition, the amount of some volatile fatty acids (VFAs) produced by the hydrothermal reaction increased as reaction temperature increased. From the phosphate release tests under anaerobic conditions, it was possible to demonstrate that not only the VFAs, but also the readily and slowly biodegradable substrates are used as potential carbon source by the phosphate-accumulating organisms (PAOs).

Keywords: $\mathrm{COD}_{\mathrm{Cr}}$ characterization enhanced biological phosphate removal (EBPR); Excess sludge; Hydrothermal reaction; Readily biodegradable substrate.
\end{abstract}

\section{INTRODUCTION}

The control of excess sludge produced in industrial and domestic wastewater treatment plants has been a matter of considerable concern. The discharge of excess sludge poses significant risks to the environment, and the development of new technologies that are capable of decreasing the pollution has challenged many research projects.

The principal methods still used in most countries are landfill and incineration. But problems such as the decline in available land for construction of new landfills and the generation of ash with a high content of heavy metals and general toxicity by the incinerators have made these methods impracticable (Wei et al., 2003). Some new technologies, such as thermal processes (Neyens and Baeyens, 2003), ozonation (Ahn et al., 2002), chlorination (Saby et al., 2002), bead mill processes (Jung et al., 2001) and reactions in high-temperature and high-pressure (HTHP) water (Shanableh, 1999), have been studied with a view to solubilizing and mineralizing the

*To whom correspondence should be addressed 
excess sludge.

Reactions in HTHP water have attracted the attention of many researchers because of the unique properties of water at elevated temperatures and pressures as reaction medium. Under HTHP conditions, the static dielectric constant of water decreases and the water becomes an excellent solvent for organic compounds. In addition, the ion product of water decreases, favoring hydrolytic reactions (Savage et al., 1995). However, HTHP water has been studied just from the viewpoint of solubilization and COD reduction of the treated excess sludge (Shanableh, 1999). Evaluations of the change in content have not yet been reported.

On the other hand, the release of some nutrients, such as nitrogen and phosphorus, has increased the problem of eutrophication in many rivers around the world. The enhanced biological phosphate removal (EBPR) process is currently considered one of the most economical ways to remove phosphate from wastewaters. The EBPR process is characterized by cycling anaerobic and aerobic conditions. In this process, phosphate removal occurs when the content of volatile fatty acids (VFAs), such as acetic and propionic acids, in the wastewater is sufficient. Under anaerobic conditions, these acids are used as carbon source by the phosphate-accumulating organisms (PAOs) to synthesize poly- $\beta$-hydroxyalkanoate (PHA), an internal storage compound. To obtain energy for PHA synthesis, the PAOs degrade the intracellular polyphosphate (polyP) granulates in the form of orthophosphate and release it into the bulk liquid. Under subsequent aerobic conditions, the PAOs use the stored PHA as carbon and energy sources and polyP is formed in excess of the levels normally required to satisfy the metabolic demand. This synthesis results in the uptake of higher levels of phosphate than that released under anaerobic conditions. Thus, a net phosphate removal can be obtained (Mino et al., 1998; Morse et al., 1998; Seviour et al., 2003). However, the VFA content in the wastewaters is not sufficient to achieve a stable phosphate removal. It is also known that only a small quantity of readily biodegradable substrate that can be easily fermented to VFAs under anaerobic conditions is present. In order to achieve stable biological phosphate removal and therefore an efficient phosphate recovery, the development of a new treatment system is required.

The objective of this work was to evaluate the feasibility of reusing the excess sludge treated in HTHP water as carbon source for the purpose of increasing the efficiency of EBPR process. In previous work (Kim et al., 2003, 2004; Quitain et al., 2002), the production of biodegradable substrates through hydrolysis of non biodegradable substrates was reported. Making use of this knowledge, excess sludge is treated in HTHP water for the purpose of obtaining biodegradable substrates through change in content of the treated excess sludge. Due to this change in content, the treated excess sludge can be recycled in the biological processes and used as carbon source for biological phosphate removal.

\section{MATERIALS AND METHODS}

\section{Sludge Samples}

Excess sludge obtained from a local fish-processing industry in Japan was used as the raw material due to its high organic content. The $\mathrm{COD}_{\mathrm{Cr}}$ and concentration of mixed-liquor suspended solids (MLSS) were $32000 \mathrm{mg} / \mathrm{L}$ and $25000 \mathrm{mg} / \mathrm{L}$, respectively. Activated sludge from an aerobic reactor was used as inoculate for water quality analysis and a phosphate release test. The concentration of MLSS and total phosphorus (TP) were $2100 \mathrm{mg} / \mathrm{L}$ and $54 \mathrm{mg} / \mathrm{L}$, respectively.

\section{Batch Reactor Apparatus}

Hydrothermal reaction was carried out using a batch reactor apparatus (TSC-006, Taiatsu Glass Corp.) that consists mainly of a stirrer, a pressure gauge, a reactor and a molten salt bath containing a mixture of potassium nitrate and sodium nitrate (Quitain et al., 2002). The batch reactor is made of hastelloy $\mathrm{C} 22$ (Ni, Cr, Mo alloy) and has a total inner volume of $65.9 \mathrm{~cm}^{3}$. The maximum operational conditions of the reactor are $450^{\circ} \mathrm{C}$ and $45 \mathrm{MPa}$.

\section{Hydrothermal Treatment of Excess Sludge}

Excess sludge was treated at reaction temperatures of $200,250,300,350$ and $400^{\circ} \mathrm{C}$ and pressures of $1.8,4.0,9.0,17.0$ and $30.0 \mathrm{MPa}$, respectively. Reaction time, defined as the time required to raise the temperature up to $90 \%$ of the reaction temperature (Kim et al., 2003), was 7 minutes for all temperatures and pressures used. Below the critical point of water $\left(374^{\circ} \mathrm{C}, 22.1 \mathrm{MPa}\right)$, saturated vapor pressures at the specific temperature were selected as liquid-phase reaction pressure. The desired pressure was obtained by adjusting the initial amount of sample, and during hydrothermal reaction, it was read with a pressure gauge located in the batch reactor. In each run, a sample was placed inside the reactor, the reactor was sealed and residual air was purged using a pure nitrogen gas stream. The reactor was placed in the preheated molten salt bath during the predetermined reaction time. Afterwards, the 
reactor was immediately quenched with a water bath, effectively stopping any ongoing reactions.

\section{Phosphate Release Test}

For the phosphate release test under anaerobic conditions, excess sludge treated by hydrothermal reaction was used as carbon source. Prior to the test, the treated excess sludge was diluted. This dilution is necessary because the high concentration of acetic and propionic acids in the treated excess sludge would rapidly exhaust the intracellular poly $\mathrm{P}$ and the ability to use $S_{S}$ or $X_{S}$ as carbon source could not be addressed. The dilution factor was calculated in order to obtain $100 \mathrm{mg}-\mathrm{BOD}_{5} / \mathrm{L}$ of the treated excess sludge. In this situation, the concentration of VFAs is low enough to release less than $5 \%$ of the TP contained in the seeding activated sludge. The mixture of treated excess sludge and the seeding activated sludge was adjusted to a specific concentration with dechlorinated tap water, and $300 \mathrm{~mL}$ of the mixed solution was placed in a flask. The air inside the flask was replaced with pure nitrogen gas and the flask was sealed. At this moment, the phosphate release test was initiated, and during 5 hours samples were taken at prescribed time intervals. A control test was also carried out using sodium acetate as sole carbon source. In this case, the carbon source was diluted in order to obtain 100 $\mathrm{mg} / \mathrm{L}$ of $\mathrm{BOD}_{5}$. It was assumed that the value of the $\mathrm{BOD}_{5}$ was $90 \%$ of the value of the theoretical oxygen demand (ThOD).

\section{Analytical Methods}

For evaluation of the products, the treated excess sludge was analyzed using an organic acid analyzer (LC-10A, Shimadzu Corp.) with two ion-exclusion columns (Shim-park SCR-102H, Shimadzu Corp.) connected in series and an electroconductivity detector (CDD-6A, Shimadzu Corp.). Total organic carbon (TOC) and dissolved organic carbon (DOC) were measured with a TOC analyzer (TOC-5000A, Shimadzu Corp.). Chemical oxygen demand $\left(\mathrm{COD}_{\mathrm{Cr}}\right)$ was analyzed with a COD analyzer consisting of a COD reactor $(\mathrm{P} / \mathrm{N} 45600-00, \mathrm{HACH}$ Corp.) and a spectrophotometer (DR/3000, HACH Corp.). Biological oxygen demand $\left(\mathrm{BOD}_{5}\right)$ was determined with a BOD tester (BOD Tester 200F, Taitec Corp.). TP, soluble phosphate $\left(\mathrm{PO}_{4}-\mathrm{P}\right)$ and MLSS were analyzed following the standard method (American Public Health Association, 1995). Before analysis of organic acid, soluble phosphate and DOC, all samples were filtered to separate solid parts using syringes and filters with a pore size of $0.45 \mu \mathrm{m}$.
For characterization of the total $\mathrm{COD}_{\mathrm{Cr}}$, the fraction of readily biodegradable substrate $\left(\mathrm{S}_{\mathrm{S}}\right)$ was based on the respirometric test, conducted in accordance with the method reported by Kappeler and Gujer (1992) and Henze et al. (1995). The fraction of slowly biodegradable substrate $\left(\mathrm{X}_{\mathrm{S}}\right)$ was defined as the difference between the value of $\mathrm{BOD}_{5}$ and the value of $\mathrm{S}_{\mathrm{S}}$. The fraction of soluble non biodegradable substrate $\left(\mathrm{S}_{\mathrm{I}}\right)$ was measured following this procedure: the activated sludge used as inoculate and the treated excess sludge were mixed in order to obtain a concentration of $\mathrm{F} / \mathrm{M}=0.1$ and placed in a flask. The tests were carried out under aerobic conditions during 8 hours. After this period of time, it was expected that all of the $\mathrm{S}_{\mathrm{S}}$ and $\mathrm{X}_{\mathrm{S}}$ content would have been completely consumed, with only the non biodegradable substrates remaining. The solution was then filtered and the $\mathrm{COD}_{\mathrm{Cr}}$ of the liquid phase was measured. The value of $\mathrm{S}_{\mathrm{I}}$ was defined as the difference between the $\mathrm{COD}_{\mathrm{Cr}}$ of the liquid phase and the $\mathrm{BOD}_{5}$. Finally, the value of particulate non biodegradable substrates $\left(\mathrm{X}_{\mathrm{I}}\right)$ was defined as the difference between the total $\mathrm{COD}_{\mathrm{Cr}}$ of the treated excess sludge and the sum of $\mathrm{S}_{\mathrm{S}}, \mathrm{X}_{\mathrm{S}}$ and $\mathrm{S}_{\mathrm{I}}$.

\section{RESULTS AND DISCUSSION}

\section{Improvement in Biodegradability}

Figure 1 shows the variations in the ratio of TOC to $\mathrm{BOD}_{5}$ for the excess sludge treated by hydrothermal reaction and the respective values for the raw material, $\mathrm{TOC}_{\mathrm{i}}$ and $\mathrm{BOD}_{5 \mathrm{i}}$.

The value of TOC at a reaction temperature of $200^{\circ} \mathrm{C}$ practically remained constant in relation to that of $\mathrm{TOC}_{\mathrm{i}}$, but the value of $\mathrm{BOD}_{5}$ was 3.8 times higher than the respective value for the raw material. In other words, after hydrothermal reaction, some non biodegradable substrates present in the raw material were degraded into biodegradable substrate.

At this reaction temperature, the increase in biodegradability was obtained without mineralization of the organic compounds. In the case of the reaction temperature of $250^{\circ} \mathrm{C}$, in spite of a higher degree of mineralization, the $\mathrm{BOD}_{5}$ did not show a significant variation. Increasing the reaction temperature to 300 , 350 and $400^{\circ} \mathrm{C}$, the $\mathrm{BOD}_{5} / \mathrm{BOD}_{5 \mathrm{i}}$ ratio remained practically constant at 3.4. On the other hand, a considerable decrease in the value of the $\mathrm{TOC} \mathrm{TOC}_{\mathrm{i}}$ ratio was obtained. Values of 0.44 and 0.22 were obtained for reaction temperatures of 350 and $400^{\circ} \mathrm{C}$, respectively. This means that when the reaction temperature was increased, mineralization of the excess sludge occurred faster than the formation of biodegradable substrates. 


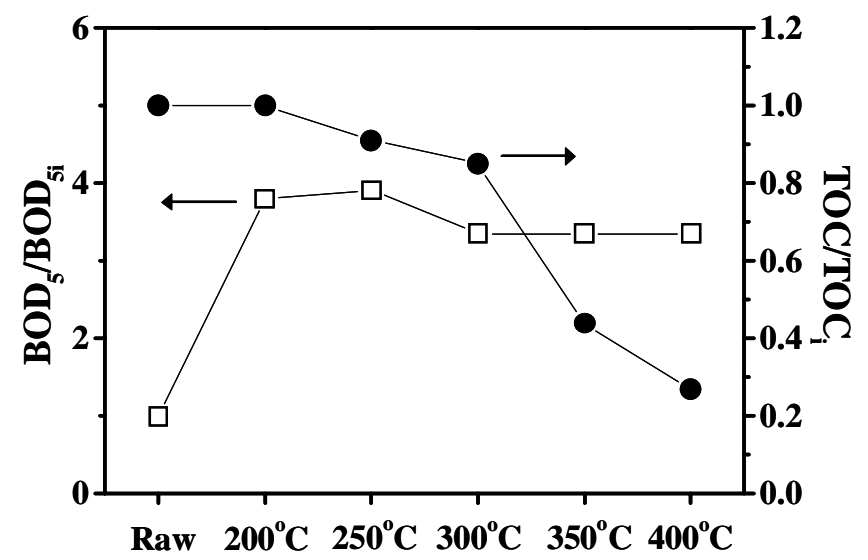

Figure 1: Effect of TOC reduction on improvement of $\mathrm{BOD}_{5}$ in excess sludge treated at 200, 250,300,350 and $400 \mathrm{oC}$ and pressures of $1.8,4.0,9.0,17.0$ and $30.0 \mathrm{MPa}$, respectively.

\section{Characterization of the Total $\mathrm{COD}_{\mathrm{Cr}}$}

Figure 2 shows the characterization of the total $\mathrm{COD}_{\mathrm{Cr}}$ of the raw material and the treated excess sludge. This characterization expresses the change in content after hydrothermal reaction. Here the total $\mathrm{COD}_{\mathrm{Cr}}$ was classified into four categories: readily biodegradable substrate $\left(\mathrm{S}_{\mathrm{S}}\right)$, slowly biodegradable substrate $\left(\mathrm{X}_{\mathrm{S}}\right)$, soluble non biodegradable substrate $\left(\mathrm{S}_{\mathrm{I}}\right)$ and particulate non biodegradable substrate $\left(\mathrm{X}_{\mathrm{I}}\right)$.

In the raw sample, approximately $90 \%$ of the total $\mathrm{COD}_{\mathrm{Cr}}$ was non biodegradable substrates, with approximately $85 \%$ being $\mathrm{X}_{\mathrm{I}}$ and only $5 \%, \mathrm{~S}_{\mathrm{I}}$. As the reaction temperature was increased, the $S_{I}$ and $X_{I}$ fractions were hydrolyzed into biodegradable substrates. Although the total fraction of non biodegradable substrates $\left(\mathrm{S}_{\mathrm{I}}+\mathrm{X}_{\mathrm{I}}\right)$ continuously decreased, the $S_{I}$ fraction increased up to a reaction temperature of $300^{\circ} \mathrm{C}$. At reaction temperatures of 350 and $400^{\circ} \mathrm{C}$, the $\mathrm{S}_{\mathrm{I}}$ fraction decreased to approximately 20 and $3 \%$ of the total $\mathrm{COD}_{\mathrm{Cr}}$, respectively. The presence of $S_{I}$ in wastewaters is undesirable because this fraction cannot be separated from the water in the settling stage and will be released into the environment. In some cases, some of the $S_{I}$ can be a precursor of compounds that are carcinogenic for human beings. Thus, a further stage in the wastewater treatment process needs to be created in order to reduce the $\mathrm{S}_{\mathrm{I}}$ fraction.

On the other hand, the fraction of $X_{S}$ increased to $34 \%$ of the total $\mathrm{COD}_{\mathrm{Cr}}$ at a reaction temperature of $200^{\circ} \mathrm{C}$ and did not change significantly when the reaction temperature was increased to $300^{\circ} \mathrm{C}$. However, at 350 and $400^{\circ} \mathrm{C}$, not only $\mathrm{X}_{\mathrm{S}}$, but also $\mathrm{S}_{\mathrm{S}}$ were obtained, particularly in the case of $400^{\circ} \mathrm{C}, 67$ and $31 \%$ of the total $\mathrm{COD}_{\mathrm{Cr}}$ was $\mathrm{S}_{\mathrm{S}}$ and $\mathrm{X}_{\mathrm{S}}$, respectively.

In the case of excess sludge treated at 200, 250 and $300^{\circ} \mathrm{C}$, where a relatively low TOC reduction was obtained, the $\mathrm{S}_{\mathrm{I}}$ and $\mathrm{X}_{\mathrm{I}}$ fractions represented more than $65 \%$ of the total $\mathrm{COD}_{\mathrm{Cr}}$. On the other hand, at 350 and $400^{\circ} \mathrm{C}$, where a relatively large $\mathrm{TOC}$ reduction was obtained, the $\mathrm{S}_{\mathrm{I}}$ and $\mathrm{X}_{\mathrm{I}}$ fractions were reduced to less than $40 \%$ of the total $\mathrm{COD}_{\mathrm{Cr}}$. Moreover, the $\mathrm{S}_{\mathrm{S}}$ fraction was produced only at reaction temperatures higher than $350^{\circ} \mathrm{C}$.

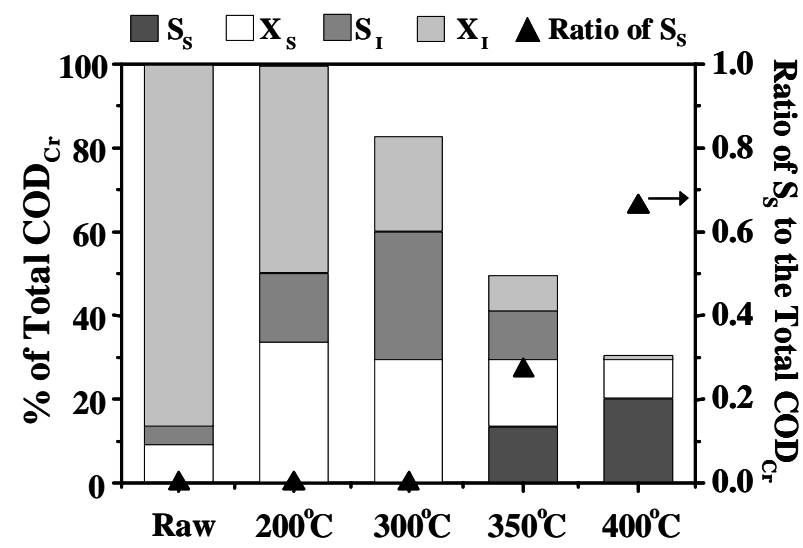

Figure 2: Change in content of the total CODCr of the excess sludge treated by hydrothermal reactions. 
Table 1: Variation in acetic and propionic acids in the treated excess sludge

\begin{tabular}{|c|c|c|c|c|c|c|}
\hline Specification & Raw & $\mathbf{2 0 0}^{\mathbf{0}} \mathbf{C}$ & $\mathbf{2 5 0}^{\mathbf{0}} \mathbf{C}$ & $\mathbf{3 0 0}^{\mathbf{}} \mathbf{C}$ & $\mathbf{3 5 0}^{\mathbf{0}} \mathbf{C}$ & $\mathbf{4 0 0}^{\mathbf{}} \mathbf{C}$ \\
\hline Acetic acid & 0 & 50 & 300 & 420 & 560 & 720 \\
Propionic acid & 0 & 0 & 250 & 350 & 170 & 50 \\
\hline
\end{tabular}

Unit: $[\mathrm{mg} / \mathrm{L}]$

\section{Effect of $S_{S}$ on the Phosphate Release Activity}

Table 1 shows the results on acetic and propionic acid concentrations in the excess sludge before and after hydrothermal reaction.

In the raw material, a zero concentration was observed for both acetic and propionic acids. However, when the reaction temperature was increased, the concentration of these acids increased, reaching a concentration of $720 \mathrm{mg} / \mathrm{L}$ at $400^{\circ} \mathrm{C}$, which is $16 \%$ of the $\mathrm{S}_{\mathrm{S}}$ fraction. On the other hand, the concentration of propionic acid increased up to a reaction temperature of $300^{\circ} \mathrm{C}$, but at higher temperatures it started to decrease. This decrease was caused by the degradation of propionic acid by hydrolytic reaction into a simpler molecular structure, i.e., acetic acid. From these results, it could be demonstrated that hydrothermal reaction can successfully produce VFAs, a carbon source essential for EBPR.

The importance of VFAs to the EBPR processes has been exhaustively studied (Mino et al., 1998). It is clear that VFAs, such as acetic and propionic acids, are directly used as carbon source by the PAOs. However, the ability to use $\mathrm{S}_{\mathrm{S}}$ or $\mathrm{X}_{\mathrm{S}}$ as carbon source to obtain stable phosphate removal has not yet been elucidated. In the $\mathrm{S}_{\mathrm{S}}$ fraction, not only the VFAs, but also other substrates that can be readily fermented into VFAs by the microorganisms, are included. On the other hand, the $\mathrm{X}_{\mathrm{S}}$ fraction cannot be directly consumed by the microorganisms, but it is known that it can be used as carbon source after extra cellular hydrolytic reactions. These reactions

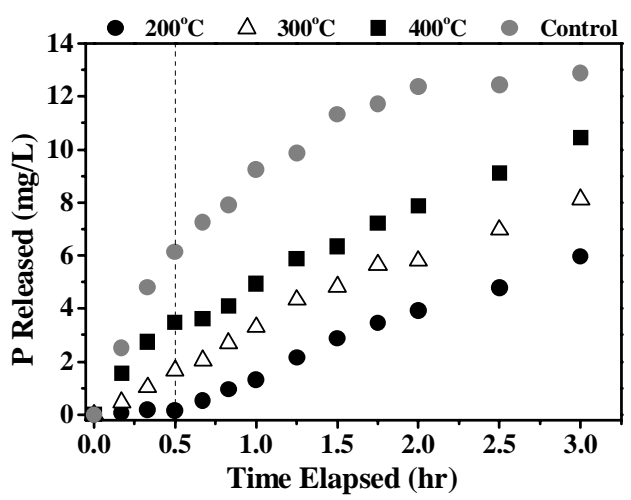

Figure 3: Phosphorus release tests under anaerobic conditions using treated excess sludge as carbon source. transform $\mathrm{X}_{\mathrm{S}}$ into $\mathrm{S}_{\mathrm{S}}$, and the latter is then fermented to form VFAs. Therefore, the capacity of PAOs to use $\mathrm{S}_{\mathrm{S}}$ or $\mathrm{X}_{\mathrm{S}}$ as carbon source needs to be studied.

Figure 3 shows the results of phosphate release tests under anaerobic conditions. The treated excess sludge was used as carbon source.

A control test was also carried out using sodium acetate as sole carbon source in order to verify the EBPR activity of the activated sludge. From the results of phosphate release in the first half hour of the test, the phosphate release rate was estimated at $3.7 \mathrm{mg}-\mathrm{P} / \mathrm{g}-\mathrm{SS} .(1 / 2 \mathrm{hr})$. This suggests that the activated sludge had sufficient EBPR activity. The overall phosphate released in the tests using the treated excess sludge as carbon source was lower than that released in the control test. However, the initial concentration of VFAs in the treated excess sludge is different from that in the control, and thus the results cannot be directly compared.

From the results, the highest overall phosphate release was obtained for the excess sludge treated at $400^{\circ} \mathrm{C}$, followed by that treated at $300^{\circ} \mathrm{C}$. In addition, an appreciable difference in the slope of the phosphate release trend was obtained in the first half hour of the test. For the excess sludge treated at $400^{\circ} \mathrm{C}$, the slope obtained was higher than those for the sludge treated at 300 and $200^{\circ} \mathrm{C}$. In this time period, the PAOs used the VFAs as carbon source and released phosphate into the bulk liquid. The VFAs were completely consumed from the medium, as can be observed in Figure 4, which shows the variation in concentration of acetic acid in the medium during the phosphate release test.

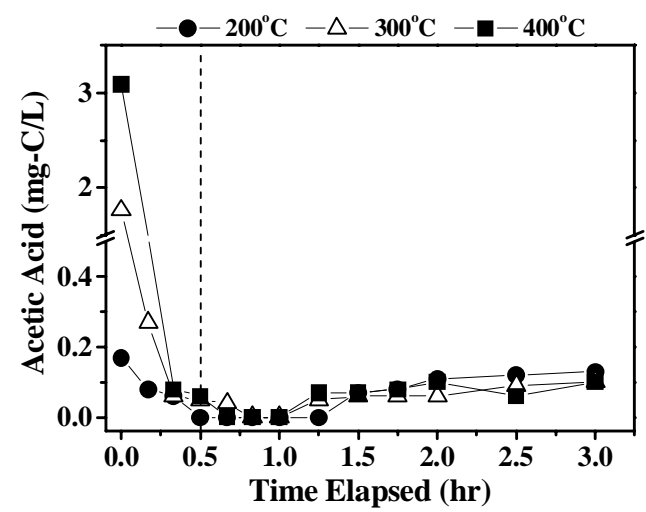

Figure 4: Consumption of acetic acid in the phosphorus release tests using the treated excess sludge as carbon source. 
In the first half hour, the concentration of acetic acid dropped to a value near zero as a result of its consumption by the PAOs. However, after this time period, phosphate was still being released. It is suggested that the fermentation of $\mathrm{S}_{\mathrm{S}}$ to acetic acid caused a continuous release of phosphate. In other words, as the $\mathrm{S}_{\mathrm{S}}$ was fermented, the acetic acid produced was mostly used as carbon source and phosphate continued to be released. The excess acetic acid produced was then released into the bulk liquid.

Using excess sludge treated at $200^{\circ} \mathrm{C}$, only 0.14 $\mathrm{mg} / \mathrm{L}$ of phosphate was released in the first half hour, since the concentration of VFAs in the medium was very low. After this time period, phosphate release by hydrolysis of $\mathrm{X}_{\mathrm{S}}$ started. Lower overall phosphate release was then obtained, since the hydrolysis of $X_{S}$ took place in two steps. First, the $\mathrm{X}_{\mathrm{S}}$ was hydrolyzed into $S_{S}$ and then the $S_{S}$ was fermented and the acetic acid formed was used as carbon source by the PAOs.

The results obtained in the phosphate release tests demonstrate that the $\mathrm{S}_{\mathrm{S}}$ and $\mathrm{X}_{\mathrm{S}}$ fractions produced by hydrothermal reaction can be a potential carbon source for the PAOs.

\section{CONCLUSIONS}

The possibility of reusing excess sludge treated by hydrothermal reaction as carbon source for EBPR processes was studied. Excess sludge obtained from a fish-processing industry located in Japan was treated in HTHP water and the improvement in biodegradability and the change in content of the total $\mathrm{COD}_{\mathrm{Cr}}$ were addressed. The results showed that when the reaction temperature was increased, the $\mathrm{X}_{\mathrm{S}}$ and $\mathrm{S}_{\mathrm{S}}$ fractions increased, reaching values of 31 and $67 \%$ of the total $\mathrm{COD}_{\mathrm{Cr}}$, respectively, for the excess sludge treated at $400^{\circ} \mathrm{C}$. In the $\mathrm{S}_{\mathrm{S}}$ fraction, $16 \%$ were composed of acetic acid, an essential carbon source for the PAOs. In addition, phosphate release tests were carried out under anaerobic conditions. The results demonstrated that not only are VFAs used as carbon source, but also that phosphate release occurred by fermentation of $S_{S}$ or hydrolysis of $X_{S}$ in the absence of VFAs in the medium. These results provide important evidence that encourages the reuse of treated excess sludge as carbon source for EBPR processes.

\section{ACKNOWLEDGEMENTS}

The authors are grateful for the financial support provided by the Industrial Technology Research
Grant Program from the New Energy and Industrial Technology Development Organization (NEDO) of Japan in the form of grant 01A42017c and the research grant in Ecological Engineering for Homeostatic Human Activity from The 21st Century COE Program of the Ministry of Education, Culture, Sports, Science and Technology (Japan). The authors also wish to acknowledge the financial support provided by the Ministry of Education, Culture, Sports, Science and Technology (Japan) and by the Capes (Brazil). Dr. Rahoma S. Mohamed passed away on April 23 $3^{\text {rd }}, 2004$.

\section{REFERENCES}

Ahn K.H., Yeom I.T., Park K.Y., Maeng S.K., Lee Y., Song K.G. and Hwang J.H., Reduction of sludge by ozone treatment and production of carbon source for denitrification, Water Science and Technology, 46, No. 11-12, 121 (2002).

Henze M., Gujer W., Mino T., Matsuo T., Wentzel M.C. and Marais G.V.R., Wastewater and biomass characterization for the activated sludge model No. 2: biological phosphorus removal, Water Science and Technology, 31, No. 2, 13 (1995).

Jung J., Xing X.H. and Matsumoto K., Kinetic analysis of excess activated sludge by dyno mill and characteristics of protein release for recovery of useful materials, Biochemical Engineering Journal, 8, 1 (2001).

Kappeler J. and Gujer W., Estimation of kinetic parameters of heterotrophic biomass under aerobic conditions and characterization of wastewater for activated sludge model, Water Science and Technology, 25, No. 6, 125 (1992).

Kim K., Fujita M., Daimon H. and Fujie K., Biodegradability improvement and structural conversion of polyvinyl alcohol (PVA) by suband supercritical water reaction, Journal of Chemical Engineering of Japan, 37, No. 6, 744 (2004).

Kim K., Fujita M., Daimon H. and Fujie K., New feasibility of hydrothermal reaction for the conversion of monochloroacetic acid to biodegradable organic acid. IWA Asia-Pacific Regional Conference Asian Waterqual 2003. Bangkok, Thailand (2003).

Mino T., van Loosdrecht M.C.M. and Heijnen J.J., Microbiology and biochemistry of the enhanced biological phosphate removal process, Water Research, 32, 3193 (1998).

Morse G.K., Brett S.W., Guy J.A. and Lester J.N., 
Review: phosphorus removal and recovery technologies, The Science of the Total Environment, 212, 69 (1998).

Neyens E. and Baeyens J., A review of thermal sludge pre-treatment process to improve dewaterability, Journal Hazardous Material, B98, 51 (2003).

Quitain A.T., Sato N., Daimon H. and Fujie K., Production of valuable materials by hydrothermal treatment of shrimp shells, Industrial \& Engineering Chemistry Research, 40, 5885 (2002).

Saby S., Djafer M. and Chen G.H., Feasibility of using a chlorination step to reduce excess sludge in activated sludge process, Water Research, 36, 656 (2002).

Savage P.E., Gopalan S., Mizan T.I., Martino C.J. and Brock E.E., Reactions at supercritical conditions: applications and fundamentals, AIChE Journal, 41, No. 7, 1723 (1995).

Seviour R.J., Mino T. and Onuki M., The microbiology of biological phosphorus removal in activated sludge systems, FEMS Microbiology Reviews, 27, 99 (2003).

Shanableh, A., Production of useful organic matter from sludge using hydrothermal treatment, Water Research, 34, No. 3, 945 (1999).

Standard Methods for the Examination of Water and Wastewater. American Public Health Association /American Water Works Association/Water Environment Federation. Washington DC, USA (1995).

Wei Y., Houten R.T.V., Borger A.R., Eikelboom D.H. and Fan Y., Minimization of excess sludge production for biological wastewater treatment, Water Research, 37, 4453 (2003). 